\title{
A Climatology of Wintertime Barrier Winds off Southeast Greenland
}

\author{
B. E. HARDEN AND I. A. RENFREW \\ University of East Anglia, Norwich, United Kingdom \\ G. N. Petersen \\ Icelandic Met Office, Reykjavik, Iceland
}

(Manuscript received 6 October 2010, in final form 23 February 2011)

\begin{abstract}
A climatology of barrier winds along the southeastern coast of Greenland is presented based on $20 \mathrm{yr}$ of winter months (1989-2008) from the ECMWF Interim Reanalysis (ERA-Interim). Barrier wind events occur predominantly at two locations: Denmark Strait North (DSN; $\left.67.7^{\circ} \mathrm{N}, 25.3^{\circ} \mathrm{W}\right)$ and Denmark Strait South (DSS; $64.9^{\circ} \mathrm{N}, 35.9^{\circ} \mathrm{W}$ ). Events stronger than $20 \mathrm{~m} \mathrm{~s}^{-1}$ occur on average once per week during winter with considerable interannual variability - from 7 to 20 events per winter. The monthly frequency of barrier wind events correlates with the monthly North Atlantic oscillation (NAO) index with a correlation coefficient of 0.57 (0.31) at DSN (DSS). The associated total turbulent heat fluxes for barrier wind events (area averaged) were typically about $200 \mathrm{~W} \mathrm{~m}^{-2}$ with peak values of $400 \mathrm{~W} \mathrm{~m}^{-2}$ common in smaller regions. Area-averaged surface stresses were typically between 0.5 and $1 \mathrm{~N} \mathrm{~m}^{-2}$. Total precipitation rates were larger at DSS than DSN, both typically less than $1 \mathrm{~mm} \mathrm{~h}^{-1}$. The total turbulent heat fluxes were shown to have a large range as a result of a large range in 2-m air temperature. Two classes of barrier winds-warm and cold-were investigated and found to develop in different synoptic-scale situations. Warm barrier winds developed when there was a blocking high pressure over the Nordic seas, while cold barrier winds owed their presence to a train of cyclones channeling through the region.
\end{abstract}

\section{Introduction}

Greenland presents a high, steep, and cold topographic barrier to the atmosphere. Its ice sheet, which covers $80 \%$ of the landmass, is responsible for the Greenland plateau being higher than $3000 \mathrm{~m}$ above sea level. This large, cold mass is capable of diverting and distorting atmospheric flow around it, forcing a number of intermittent, lowlevel, high-velocity wind events, such as westerly and easterly tip jets (Doyle and Shapiro 1999; Moore 2003; Moore and Renfrew 2005, hereafter MR05; Våge et al. 2009; Renfrew et al. 2009a; Outten et al. 2009, 2010), barrier winds (MR05; Petersen et al. 2009) and katabatic/ downslope winds (Heinemann and Klein 2002; Klein and Heinemann 2002). It also has influences on the development of polar lows (Martin and Moore 2006), cyclogenesis (Petersen et al. 2003; Serreze et al. 1997),

Corresponding author address: Benjamin Harden, School of Environmental Sciences, University of East Anglia, Norwich NR4 7TJ, United Kingdom.

E-mail: b.harden@uea.ac.uk cyclolysis (Hoskins and Hodges 2002; Serreze et al. 1997), and the properties of cyclones that pass through the region (Kristjánsson and McInnes 1999; Skeie et al. 2006).

Not only are the low-level wind events produced by Greenland responsible for some of the stormiest seas in the world's oceans (Sampe and Xie 2007; Moore et al. 2008) producing hazardous maritime conditions, but interest has been piqued recently into the possible influence that these intermittent events have on the ocean in a region that is vital for the thermohaline circulation. For example, westerly tip jets (produced around the southern tip of Greenland) have been shown to be capable of triggering deep convection in the Irminger Sea (Pickart et al. 2003; Våge et al. 2008). The knowledge that intense, but intermittent, wind phenomena can have a protracted impact on the slow overturning circulation of the Atlantic Ocean points to the importance of understanding the prevalent atmospheric conditions and ocean forcing in the region.

The subject of this study is barrier winds-low-level jets produced when air is forced toward a high and 
steep topographic barrier (such as Greenland) with a large nondimensional mountain height, $N h / U$, where $N$ is the Brunt-Väisälä frequency, $h$ is the mountain height, and $U$ is the upstream wind speed (Schwerdtfeger 1975; Parish 1983; Pierrehumbert and Wyman 1985). The air, unable to ascend the barrier, is dammed and a pressure gradient perpendicular to the barrier develops, leading to geostrophic flow along the barrier (to first order). When the upstream winds are produced by a synopticscale cyclone, the separation of "synoptic" and "perturbation" pressure gradients is difficult (e.g., see Petersen et al. 2009). Barrier winds have been studied in situ and through numerical models at numerous mountainous locations around the world; the Antarctic Peninsula (Schwerdtfeger 1975; Parish 1983), Alaska (Loescher et al. 2006; Olson and Colle 2009), California (Cui et al. 1998), New Zealand (Revell et al. 2002), the Rockies (Colle and Mass 1995), the Sierra Nevada (Parish 1982), the Appalachians (Bell and Bosart 1988), and the Alps (Chen and Smith 1987), plus have been the subject of a number of idealized numerical studies (Braun et al. 1999; Petersen et al. 2003, 2005).

Along the coast of Greenland, barrier wind events were comprehensively observed by instrumented aircraft during the Greenland Flow Distortion Experiment (GFDex) field campaign (Renfrew et al. 2008). Petersen et al. (2009) provide an overview of two barrier wind events, including jet cross sections from dropsonde soundings, numerical simulations, and trajectory analysis. They showed that the presence of Greenland caused up to a doubling in the maximum wind speed along the coastline-with the precise synoptic-scale situation being critical for the location and magnitude of the associated barrier winds. GFDex showed how potentially important these winds could be for the ocean. In the two and a half weeks of the field campaign, three barrier wind events were observed; in one case, measured total turbulent heat fluxes exceeded $600 \mathrm{~W} \mathrm{~m}^{-2}$ and surface stresses reached $1.5 \mathrm{~N} \mathrm{~m}^{-2}$ (Renfrew et al. 2009b).

An investigation of their effects on the ocean was conducted through very high-resolution numerical modeling of the Irminger Sea and Denmark Strait by Haine et al. (2009). They showed that these barrier winds were capable of producing maximum net heat fluxes of around $600 \mathrm{~W} \mathrm{~m}^{-2}$ and a peak current of nearly $2 \mathrm{~m} \mathrm{~s}^{-1}$, and that the boundary layer depth of the ocean responds rapidly and sensitively with mean values of around $100 \mathrm{~m}$ but with maximum values as large as $500 \mathrm{~m}$. Recently, Straneo et al. (2010) showed that strong barrier winds off southeast Greenland are likely responsible for the recirculation of warm water up glacial fjords, increasing the melting of glaciers at their base and enhancing the speed of their descent into the ocean.
Tip jets and barrier winds around Greenland were the subject of the Quick Scatterometer (QuikSCAT) climatology of MR05. MR05 provided much useful information about strong wind events in the region but was limited by only having a 5-yr record over the ice-free oceans and only for 10-m winds. A lack of wind speed data over sea ice affects a large region in the north of Denmark Strait, where barrier winds are known to occur (Petersen et al. 2009). Tip jets have recently been the subject of climatologies using atmospheric reanalysis products (Sproson et al. 2008; Våge et al. 2009), but climatological knowledge of barrier winds in the region is still limited to that provided by MR05. Here we build upon that by compiling a climatology of barrier winds using state-of-the-art meteorological reanalyses, thus making use of a number of diagnostics throughout the atmosphere as well as over land and sea ice.

The aims of this study are summarized as follows:

- To extend knowledge about the frequency, strength, location, and properties of barrier winds in the region.

- To outline the impact these winds could be having on the ocean, providing the oceanic community with a useful tool for studying atmospheric forcing in the region.

\section{Data}

\section{a. Description}

Data from the European Centre for Medium-Range Weather Forecasts (ECMWF) Interim Reanalysis (ERAInterim) (Berrisford et al. 2009) were used for this study. ERA-Interim is a global reanalysis product that covers the period from 1989 to the present. A number of improvements have been made on its predecessor, the 40-yr ECMWF Re-Analysis (ERA-40). These include many model refinements along with changes in data assimilation; most significantly, a four-dimensional variational data assimilation (4D-Var) process is now used (Rabier et al. 1998).

The underlying model for ERA-Interim is ECMWF's Integrated Forecast System (IFS) cycle 31r2. This is a spectral, semi-implicit, semi-Lagrangian model with 255 spectral modes (T255) and 60 levels (L60) in the vertical. For gridpoint fields, a reduced Gaussian grid is used with an approximately uniform spacing of $80 \mathrm{~km}$ (N128). This is a marked improvement on ERA-40, which was T159, L60, and N80, so an approximate horizontal resolution of $125 \mathrm{~km}$. The improvement in horizontal resolution is crucial, for this study, to adequately resolve the relatively small-scale barrier winds. The atmosphere is coupled to an ocean wave model with 30 wave frequencies that can propagate in 24 directions. 

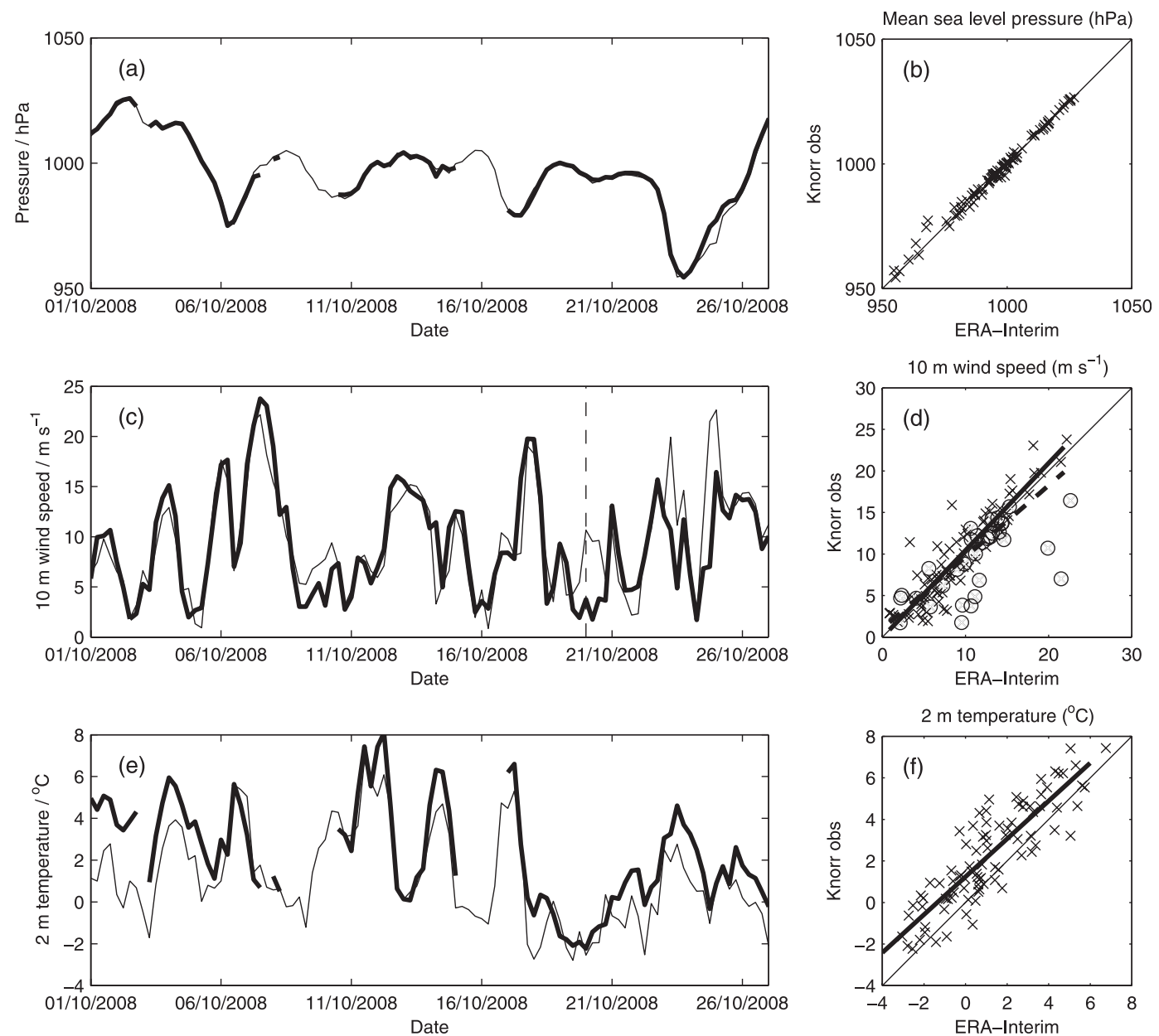

FIG. 1. (left) Comparison of time series for ERA-Interim (thin) near-surface fields with measurements made aboard the R/V Knorr in the Irminger Sea in October 2008 (thick). (right) All data points plotted on scatterplots. Thin line is perfect agreement; thick line is best linear fit to the data. (a),(b) Surface pressure (hPa); (c),(d) 10-m wind speed $\left(\mathrm{m} \mathrm{s}^{-1}\right)$; and (e),(f) 2-m temperature $\left({ }^{\circ} \mathrm{C}\right)$. (d) Crosses are data points recorded before 20 Oct 2008 [dashed line in (c)], circles are those after this date, thick dashed line is the linear regression for all data points recorded, and thick solid line is the linear regression for all times before 20 October 2008 [dashed line in (c)].

Reanalysis fields are produced 4 times daily at 0000 , 0600, 1200, and 1800 UTC. Ten-day forecasts are run twice a day, initialized at 0000 and 1200 UTC. Data are available on the 60 model levels or, as used here, interpolated onto 37 pressure levels.

\section{b. Verification}

To appreciate the strengths and limitations of ERAInterim, a verification of the output against observations is necessary. In the region of interest for this study (the subpolar seas of the North Atlantic), work has already been conducted to verify ECMWF products (Renfrew et al. 2002; Våge et al. 2009; Renfrew et al. 2009b). These studies were conducted under similar meteorological conditions to those of this study, which makes their findings particularly pertinent. These studies were examining
ERA-40 and ECMWF operational analyses (not ERAInterim); however, the underlying model dynamics are largely the same, so much of this verification should be applicable here. ECMWF products were found to perform reasonably well at the surface; however, high wind speed events were underrepresented in coarse-resolution models by up to $5 \mathrm{~m} \mathrm{~s}^{-1}$ (Våge et al. 2009; Renfrew et al. 2009b), near-surface temperatures had a systematic cold bias of around $1 \mathrm{~K}$, and the resulting heat fluxes were observed to be too large by $10 \%$ (Renfrew et al. 2009b). To confirm that these findings are relevant to ERAInterim, further verification is now presented.

Near-surface meteorological variables were collected during a research cruise in the Irminger Sea aboard the R/V Knorr in October 2008 (KN194-4). Specifically, pressure and wind speed measured by the Improved 

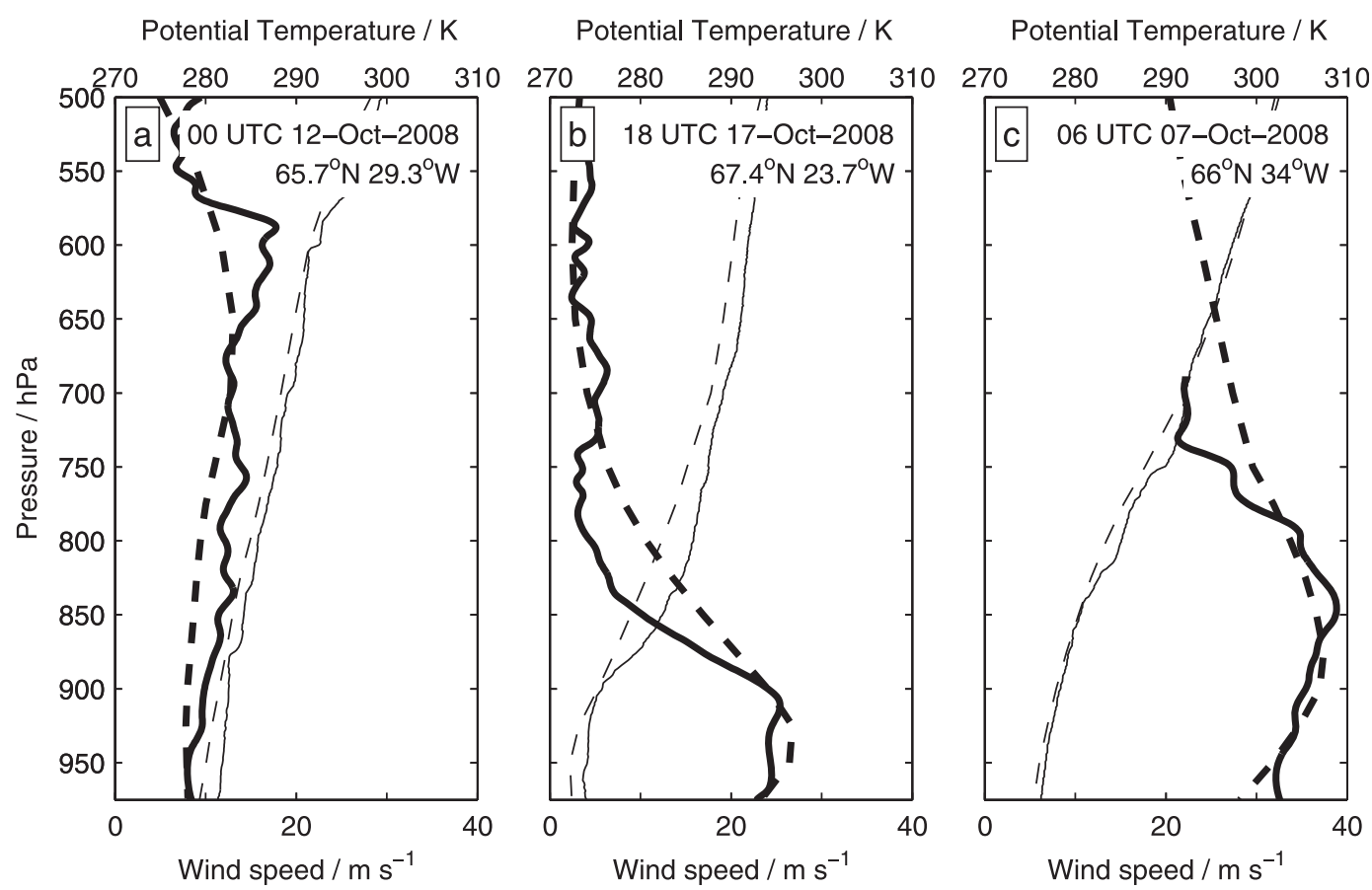

FIG. 2. Three sample radiosonde soundings (solid lines) made aboard the R/V Knorr in the Irminger Sea in October 2008 and corresponding model soundings in the ERA-Interim dataset (dashed lines). Wind speed (thick, $\mathrm{m} \mathrm{s}^{-1}$ ) and potential temperature (thin, $\mathrm{K}$ ) shown.

Meteorological (IMET) package and temperature as recorded by the Vaisala WXT5-10 system. All meteorological instruments were mounted on a tower at the bow of the ship, which put them $15.5 \mathrm{~m}$ above sea level. In all subsequent analysis, the measurements are extrapolated to the same heights as the outputs from ERA-Interim - that is, to $10 \mathrm{~m}$ for wind speed, to $2 \mathrm{~m}$ for temperature, and to the surface for pressure. This was achieved using the logarithmic neutral profile formulas for wind speed and temperature, and hydrostatic balance for pressure. Stability-dependent surface-layer formulas (Smith 1988) were also used for the wind speed and temperature reductions but few discernible differences were seen. Because of an incomplete humidity record, the neutral formulas were used.

A number of barrier winds were observed during the October 2008 cruise, making this dataset ideal for verifying the performance of ERA-Interim for this study. Figure 1 illustrates that surface pressure and the 10-m wind speed from ERA-Interim compare well with data collected on the Knorr. The ERA-Interim pressure, in particular, is in excellent agreement with the measured pressure. Strong winds are only slightly underrepresented in ERAInterim (mean bias is $-1 \mathrm{~m} \mathrm{~s}^{-1}$ ), indeed the product performs better than was found in comparing ERA-40 wind speeds with QuikSCAT (Våge et al. 2009). The thick dashed trend line in Fig. 1d shows the regression for all data points collected, but perhaps it is a little misleading. It includes points recorded after 20 October 2008 (dashed line in Fig. 1c), when the Knorr spent much of its time in coastal regions where sheltering effects often lead to stronger winds in the model than were recorded on the Knorr. These latter points are shown in Fig. 1d with circles, and the trend line excluding these points is shown as the solid line in Fig. 1d. The conclusion is that ERA-Interim represents $10-\mathrm{m}$ winds well and better than previous studies in which high wind speeds were significantly underrepresented, for example, a mean bias of $-2.5 \mathrm{~m} \mathrm{~s}^{-1}$ in Renfrew et al. (2009b).

The temperature comparison and trend line in Figs. $1 \mathrm{e}$,f show that the 2-m temperature model field has a cold bias of $2^{\circ} \mathrm{C}$, a feature seen by Renfrew et al. (2009b) when comparing observations to the ECMWF $1.125^{\circ}$ operational analysis and which they attribute to low model resolution-the feature was not there for the same comparison with the ECMWF T511 resolution model. As in that study, this is likely to produce an overestimation of surface turbulent heat fluxes. Overall, it seems that the performance of ERA-Interim at the surface is good.

To be able to say how well ERA-Interim performs with height, comparisons with radiosonde and dropsonde observations in the region of interest were conducted. Radiosondes were launched during the R/V Knorr 

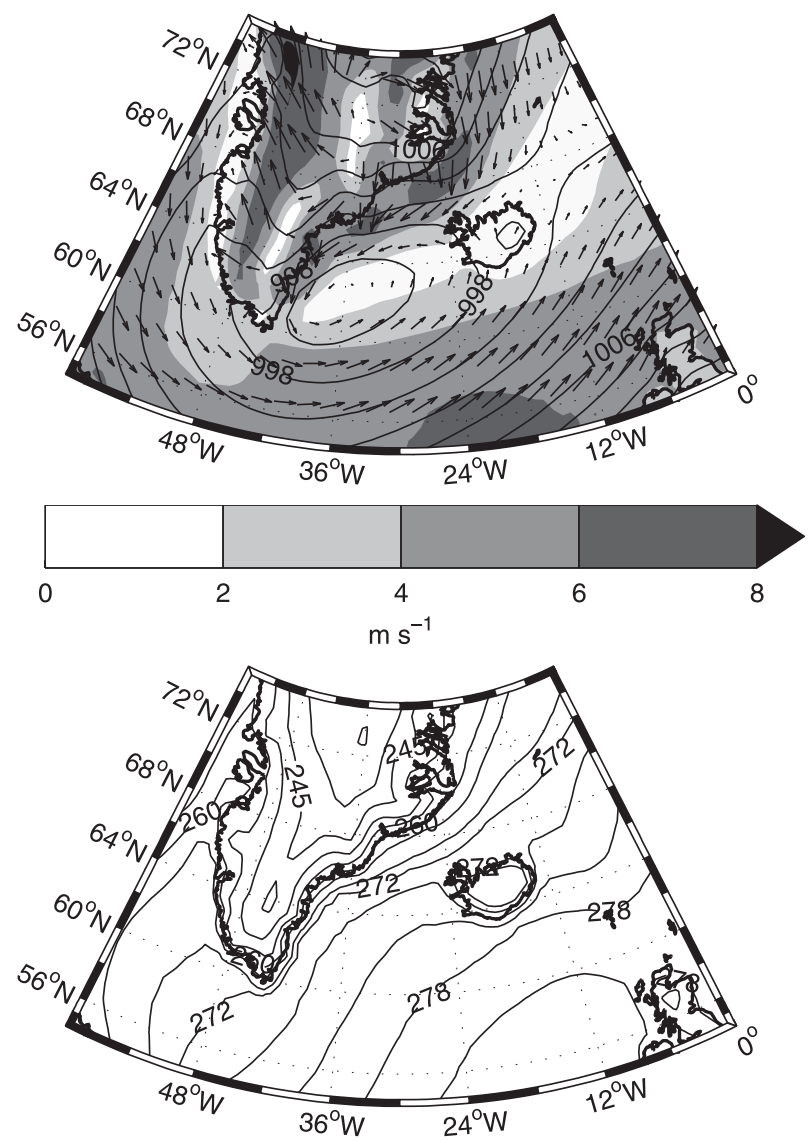

FIG. 3. (top) Mean of the 10-m wind field $\left(\mathrm{m} \mathrm{s}^{-1}\right)$ and mean sea level pressure (contours every $2 \mathrm{hPa}$ ) for ERA-Interim in DJF of 1989-2008. Wind vectors are shown at every third data point. (bottom) Mean 2-m temperature over the same period (contours every $5 \mathrm{~K}$ below $270 \mathrm{~K}$ and every $2 \mathrm{~K}$ above this value).

cruise in October 2008. Figure 2 shows three representative soundings: during low-wind conditions (Fig. 2a) and during barrier wind events (Figs. 2b,c). Under low wind speed conditions, the winds are generally well represented at all heights, while the cold bias seen at the surface extends throughout the atmospheric column. This cold bias is also observed at all heights under barrier wind conditions. The magnitude of the maximum wind speeds recorded during barrier wind conditions are mostly well captured in the ERA-Interim product; although, at some times, peak wind speeds are missed by as much as $5 \mathrm{~m} \mathrm{~s}^{-1}$. The jets were commonly observed to be capped by a strong temperature inversion (e.g., in Fig. $2 b$ ), the gradients of which were poorly captured in the model. This results in a model jet that is too broad in the vertical. Figure $2 \mathrm{c}$ shows that when a barrier wind has a weaker temperature inversion, the vertical gradients in the measured wind speed are reduced and the performance of ERA-Interim improves.
Comparisons were also made between ERA-Interim and the cross sections shown in Petersen et al. (2009). These used dropsonde observations during barrier wind conditions in the Denmark Strait during GFDex (not shown). These comparisons yielded similar features to those seen in Fig. 2. The magnitude and vertical structure of the barrier winds were generally well represented, although peak winds in the jet core and sharp vertical gradients were occasionally too weak. The fact that the general magnitude of the jet is captured is an indication that the horizontal resolution is sufficient to adequately resolve these features.

What we have learned from these verifications and from previous studies is that the ERA-Interim product is most accurate at the surface, where wind speed, temperature, and fluxes are generally well represented. The resolution is sufficient to resolve barrier jets, although care should be taken when interpreting their vertical structure which, although capturing the basic structure, will not necessarily capture the strength of the vertical gradients.

\section{Near-surface climatology}

The near-surface fields from ERA-Interim winters [December-February (DJF)] between 1989 and 2008 are used to draw a climatological picture of the mean state in the region. The winter period was chosen for study because of the increased frequency of strong wind events at this time (Sampe and Xie 2007) and the importance of this period for ocean processes (Våge et al. 2008). In Fig. 3, a large climatological low pressure system can be seen over the Irminger Sea, consistent with the climatological Icelandic low (Sahsamanoglou 1990; Serreze et al. 1997). This forces a climatological jet of $\sim 5 \mathrm{~m} \mathrm{~s}^{-1}$ running the length of the southeastern coast of Greenland. Along this jet sits isolated bullets in excess of $6 \mathrm{~m} \mathrm{~s}^{-1}$, the site of which two bullets (at $66^{\circ} \mathrm{N}$, $34^{\circ} \mathrm{W}$ and $69^{\circ} \mathrm{N}, 23^{\circ} \mathrm{W}$ ) agree well with the locations for barrier winds highlighted in MR05 and have magnitudes in good agreement with MR05. A third location of high wind is evident farther to the southwest at $65^{\circ} \mathrm{N}, 41^{\circ} \mathrm{W}$, its location encroaching onto the land and with a larger offshore component than the other two bullets. This outflow could be partly influenced by katabatic and downslope winds, which are common occurrences in this region (Heinemann and Klein 2002; Klein and Heinemann 2002), or be part of the downslope flow associated with westerly tip jets (Doyle and Shapiro 1999). There is also a strong southerly flow over much of the western slopes of Greenland.

Also shown in Fig. 3 is the climatological mean 2-m temperature. The warmest air is found in the southeastern 


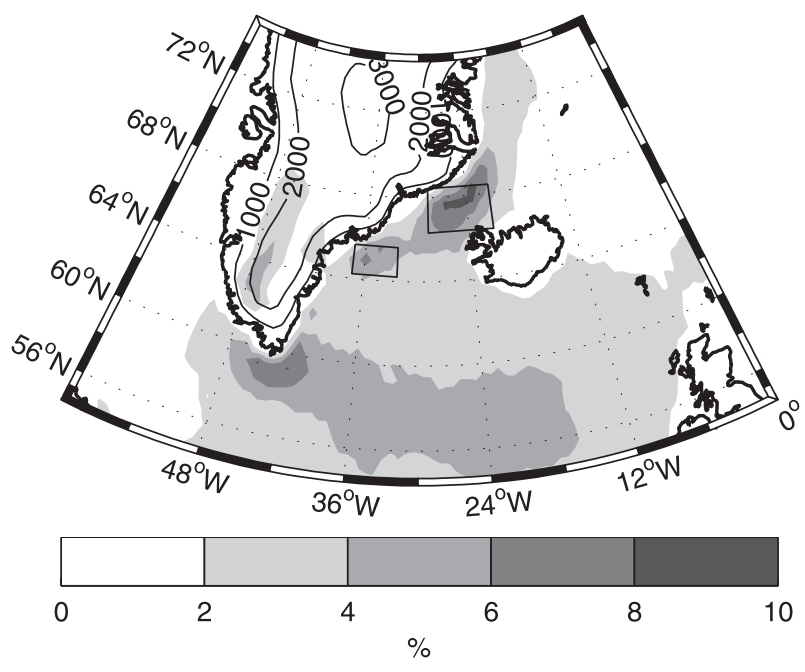

FIG. 4. Percentage of time that the 10-m wind speed is in excess of $20 \mathrm{~m} \mathrm{~s}^{-1}$ at each location in the domain for ERA-Interim in DJF of 1989-2008. Shading every $2 \%$. Boxes mark the locations of DSS and DSN. ERA-Interim orography is shown with contours; contour interval is $1000 \mathrm{~m}$.

part of the domain, reflecting the climatological sea surface temperature pattern. The temperature decreases to the north with the strongest gradient in temperature over the ocean (the Arctic Front) occurring along the southeastern Greenland coast, where the mean 2-m temperature is below freezing in the region represented by the climatological jet. The very low temperatures over Greenland's interior are due to the combined influences of the ice sheet and altitude.

The fraction of time the wind speed exceeds $20 \mathrm{~m} \mathrm{~s}^{-1}$ at each location in the domain is shown in Fig. 4. The threshold of $20 \mathrm{~m} \mathrm{~s}^{-1}$ was arbitrarily chosen as the criterion for strong winds for this analysis, although qualitatively similar patterns are seen for other thresholds. This is a smaller threshold than used in MR05, but it was chosen to take into consideration QuikSCAT's tendency to overestimate strong winds (e.g., Ebuchi et al. 2002; Moore et al. 2008). As with the analysis of MR05, three coastal locations of frequent high winds are clear: two along Greenland's southeastern coast and a third at Cape Farewell. The two northerly locations correspond to the locations of frequent barrier winds and the third location to frequent tip jets. At each location, wind speeds exceed $20 \mathrm{~m} \mathrm{~s}^{-1}$ more than $6 \%$ of the time, in some places as much as $10 \%$ of the time.

In the remainder of this study, we focus on the two northerly sites. See MR05, Sproson et al. (2008), and Våge et al. (2009) for a climatological analysis of the Cape Farewell site.

\section{Barrier wind detection}

\section{a. Method}

Barrier winds are characterized by strong winds directed parallel to the coast . Therefore, in this study of southeast Greenland, a barrier wind event is defined if at any time the $10-\mathrm{m}$ wind speed at a location is in excess of a threshold wind speed and directed between northerly $\left(0^{\circ} \mathrm{N}\right)$ and easterly $\left(90^{\circ} \mathrm{N}\right)$. Note that this pragmatic definition does not take into account the flow dynamics, but it is nonetheless useful in capturing what have previously been shown to be barrier flows in the region (e.g. MR05, Petersen et al. 2009). Furthermore, the proximity to the steep topography of Greenland makes it very unlikely that strong winds detected in this way will have been produced without feeling the influence of the barrier in some way.

Following MR05, the locations that will be used for barrier wind detection are the two maxima in frequency of high wind speed events (Fig. 4). These maxima correspond to the Denmark Strait South (DSS) and Denmark Strait North (DSN) locations identified in MR05 and for consistency, the same nomenclature will be used here. Instead of using a point measurement for detecting barrier winds like MR05, a region that encompasses the maxima will be used (marked by boxes in Fig. 4). These regions have been selected to not include any land grid points.

The steps in the detection routine for each region are as follows:

- At each time, the maximum $10-\mathrm{m}$ wind speed in the region, for which the wind direction is between northerly $\left(0^{\circ} \mathrm{N}\right)$ and easterly $\left(90^{\circ} \mathrm{N}\right)$, is found and a time series is constructed from these values. Note that using a larger range of wind directions resulted in a similar number of detected events.

- The maxima in this time series greater than $20 \mathrm{~m} \mathrm{~s}^{-1}$ are selected. Different threshold values give qualitatively similar results.

- Finally, for a maximum to be defined as a barrier wind event, it must be distinct in time, that is, separate from other maxima by more than $24 \mathrm{~h}$. If wind speed maxima greater than $20 \mathrm{~m} \mathrm{~s}^{-1}$ are separated by less than $24 \mathrm{~h}$, then the time of the peak wind speed is chosen.

\section{b. Results}

Applying the detection routine described above results in the detection of 252 barrier wind events at DSS and 291 events at DSN over the 60-month period (December-February between 1989 and 2008). This is approximately one barrier wind event a week for each 


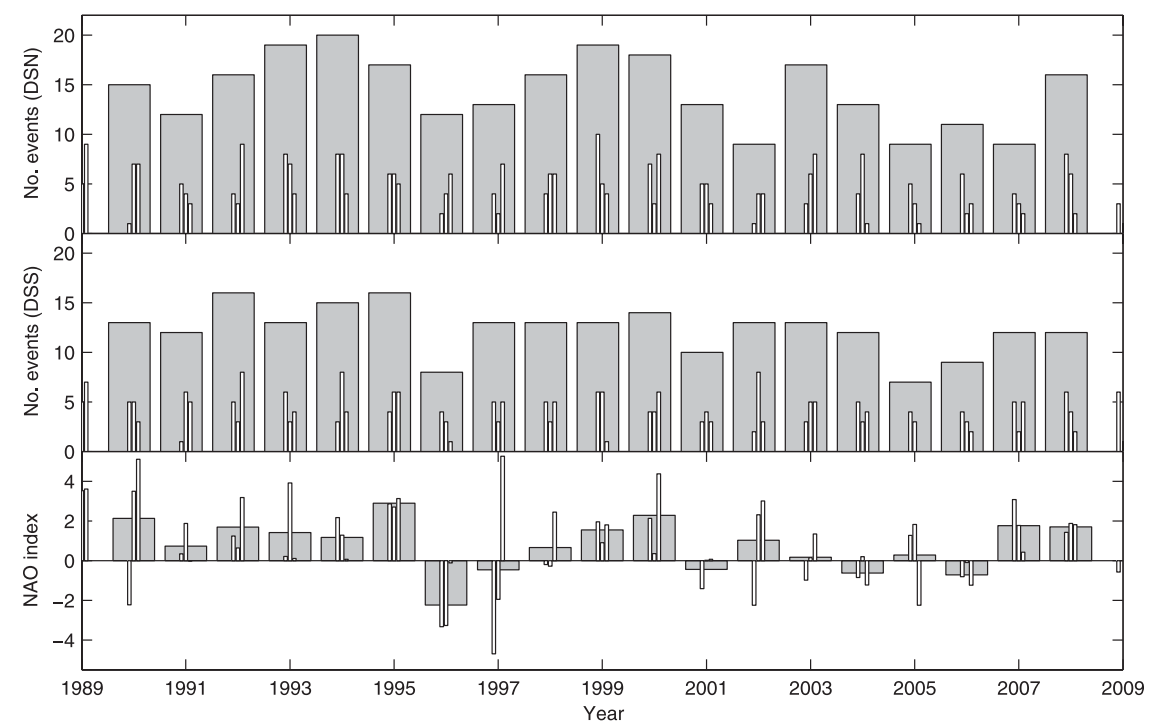

FIG. 5. (top),(middle) Number of barrier wind events detected per winter month (narrow white bars) and winter season (gray bars); (top) is for DSN and (middle) is for DSS. (bottom) NAO index by winter month (white bars) and winter season (gray bars).

location during these months. This can be compared to Våge et al. (2009), who observed roughly one westerly tip jet per two weeks in their ERA-40-based climatology. A similar number of barrier events at each location are slightly surprising, considering the difference in frequency of high winds observed between the two locations in Fig. 4 (around $5 \%$ at DSS and $8 \%$ at DSN) - the implication being that each event lasts longer at DSN than at DSS.

There exists a discrepancy between the mean frequency of barrier wind events in this study and in MR05. The 47 barrier wind events detected by MR05 in $5 \mathrm{yr}$ (one barrier wind event a week) at DSS agrees well with the frequency observed by this study, but MR05 observed only 19 events at DSN. This discrepancy could be partly explained by the point method of MR05 compared with the area method used here; however, a more likely explanation is that MR05 is based on measurements from QuikSCAT, which cannot measure $10-\mathrm{m}$ wind speeds above sea ice-this is much more prevalent at DSN than at DSS.

To investigate interannual variability, Fig. 5 shows the number of barrier wind events detected each month and each winter season for the two locations. Both locations experience a degree of year-to-year variability, but at DSN it is larger (a standard deviation of 3.5 compared with 2.4 at DSS). There is a reasonable correlation of $0.43(0.64)$ between the number of barrier wind events at each location each month (winter season). Looking at individual months, it appears that no one month is particularly favored for the prevalence of barrier winds.

Also shown in Fig. 5 is the monthly and mean winter (DJF) North Atlantic Oscillation (NAO) index of Hurrell
(1995). There is a positive correlation between the monthly NAO index and the monthly frequency of barrier wind events at both locations with correlation coefficients of 0.31 at DSS and 0.57 at DSN, both of which are statistically significant at a $99 \%$ confidence level. This is not entirely surprising considering high NAO indices are forced by a deeper Icelandic low, the result of more frequent and deeper cyclones, which are likely to produce more and stronger barrier winds. Correlation with the monthly southwestern Iceland mean sea level pressure [used in calculating the NAO index of Hurrell (1995)] yields a similar result but with slightly better correlations-coefficients of -0.37 and -0.67 are found at DSS and DSN, respectively. These correlations could be useful in reconstructing barrier wind frequency for times before meteorological reanalysis coverage, but for which we have reliable NAO and mean sea level pressure data.

It has been shown that there is a correlation between the interannual variability at DSS and DSN. A sensible question at this point seems to be, is there a causal relationship between events at DSS and those at DSN? Figure 6 shows how many events at DSS are succeeded by an event at DSN within a certain lag time. It can be seen that 30 of the 252 detected events at DSS are concurrent with an event at DSN (approximately 12\%). The maximum in the figure (44 events) occurs at a lag time of $6 \mathrm{~h}$. This means that $17 \%$ of the time, an event at DSS is succeeded by an event at DSN by $6 \mathrm{~h}$. This implies retrograde propagation of the event; the region of strong winds travels northeastward up the coast 


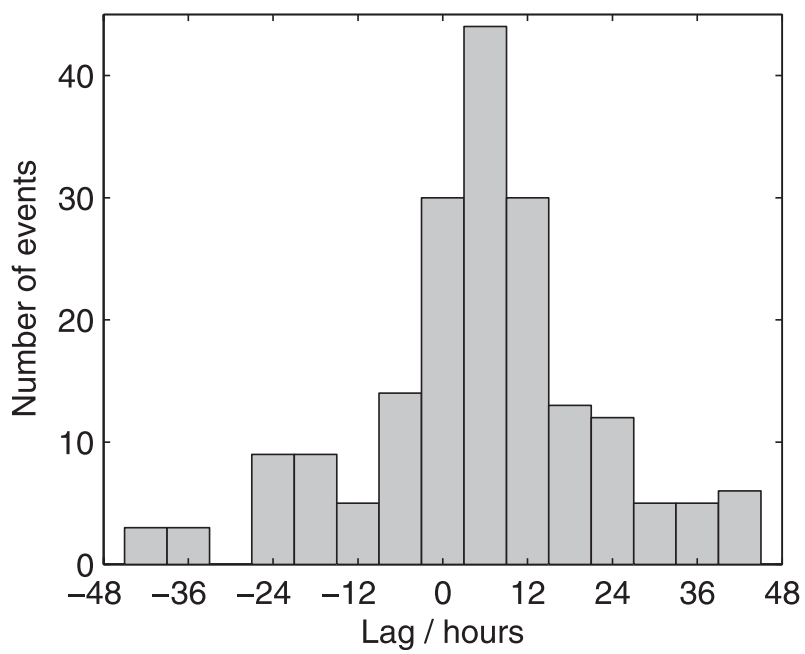

FIG. 6. Histogram of lag time between barrier wind events at DSS and DSN. A positive (negative) lag indicates that the event at DSN occurred after (before) the event at DSS.

(seemingly against the along-barrier flow). The reason this lag exists is because of the common northeastward propagation of cyclones through the region (e.g., Hoskins and Hodges 2002). It is logical to suggest that as a cyclone moves through the region, an event is triggered first at DSS and subsequently at DSN. This result is evidence that barrier winds off Greenland are the result of the direct influence of Greenland's topography on cyclones. The total number of events within $\pm 24 \mathrm{~h}$ of the peak will give an upper limit on the number of causally linked events because this period is typical of the passage of a cyclone through the region. This criterion results in 162 events $(65 \%)$, meaning that the upper limit of causally linked events is around two-thirds of the total number of events at DSS.

The 2-m temperature was extracted for each event at the DSN and DSS locations (Fig. 7). The thick dashed line shows the climatological (DJF) mean for the two locations (i.e., the boxes in Fig. 4). What is clear is that the median barrier wind event temperature is not significantly different from the climatological mean temperature over the entire 60-month period of study at each location. Around this mean value though, both locations exhibit quite a large range. At DSS, much of the variance is contained within a 4-K range of the median value, $274 \mathrm{~K}$; however, temperatures can be as high as $278 \mathrm{~K}$ or as low as $263 \mathrm{~K}$ in extreme cases. At DSN, the temperatures are generally colder because of the more northerly location of the region and also the increased access to cold Arctic air that is available to the northeast of the Denmark Strait. The distribution is similar, although the range is somewhat larger; in particular, a cold tail is more exaggerated at DSN, with

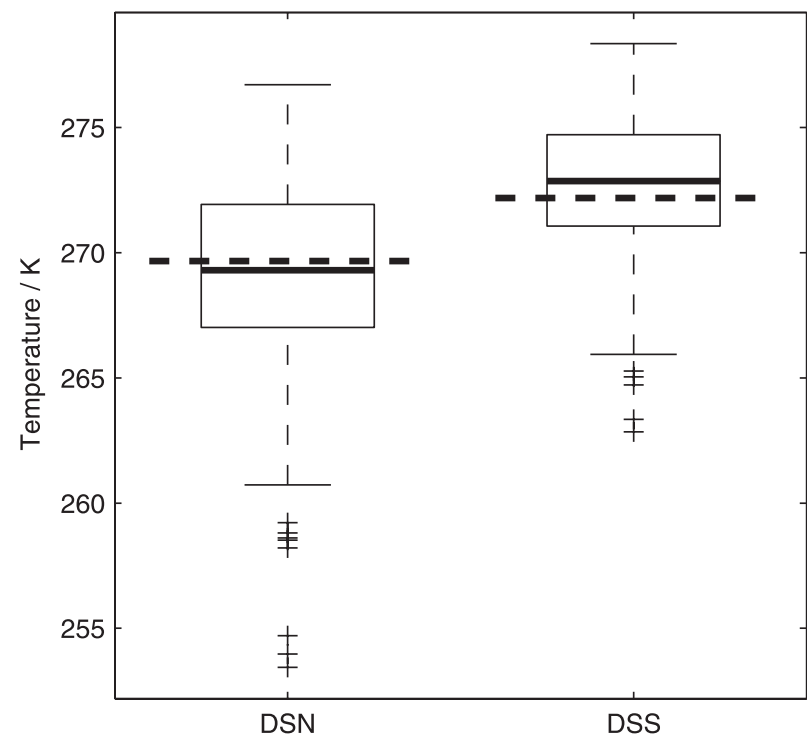

FIG. 7. 2-m temperature (K) for all barrier wind events detected at DSS and DSN. Thick horizontal line is the median, box indicates first and third quartiles, and bars extend to the minimum and maximum of the dataset. Crosses mark outliers defined as being 1.5 interquartile ranges outside of a quartile. Thick horizontal dashed line is the climatological mean temperature for each region.

temperatures lower than $255 \mathrm{~K}$ in extreme cases. Not only are the median temperatures at each location comparable to their respective climatological means, but the range of barrier wind temperatures is also comparable to the climatological range observed throughout the 60-month period (not shown). This implies that barrier winds bring about no special temperature regime; they cannot be said to be generally "cold" or "warm" winds. A further discussion of barrier wind temperatures is addressed later, in section 7 .

\section{Composite analysis}

Mean composite fields have been produced for the 291 barrier winds detected at DSN and the 252 at DSS. Looking first at the mean 10-m wind field in Fig. 8, we can see that at both locations, the composite barrier wind speed peaks at about $20 \mathrm{~m} \mathrm{~s}^{-1}$ with a width of $200 \mathrm{~km}$. The lengths of the composite barrier winds are $450 \mathrm{~km}$ at DSN and $700 \mathrm{~km}$ at DSS (as defined by the $15 \mathrm{~m} \mathrm{~s}^{-1}$ contour). Importantly for DSS, much of the region of strong winds is located upwind of the maximum, emphasizing the number of events at DSS that occurs concurrently (or \pm a small time lag), with events further upstream at DSN. Comparing with MR05's composites, the only substantial difference is that in this study, the barrier wind composites are well defined over 

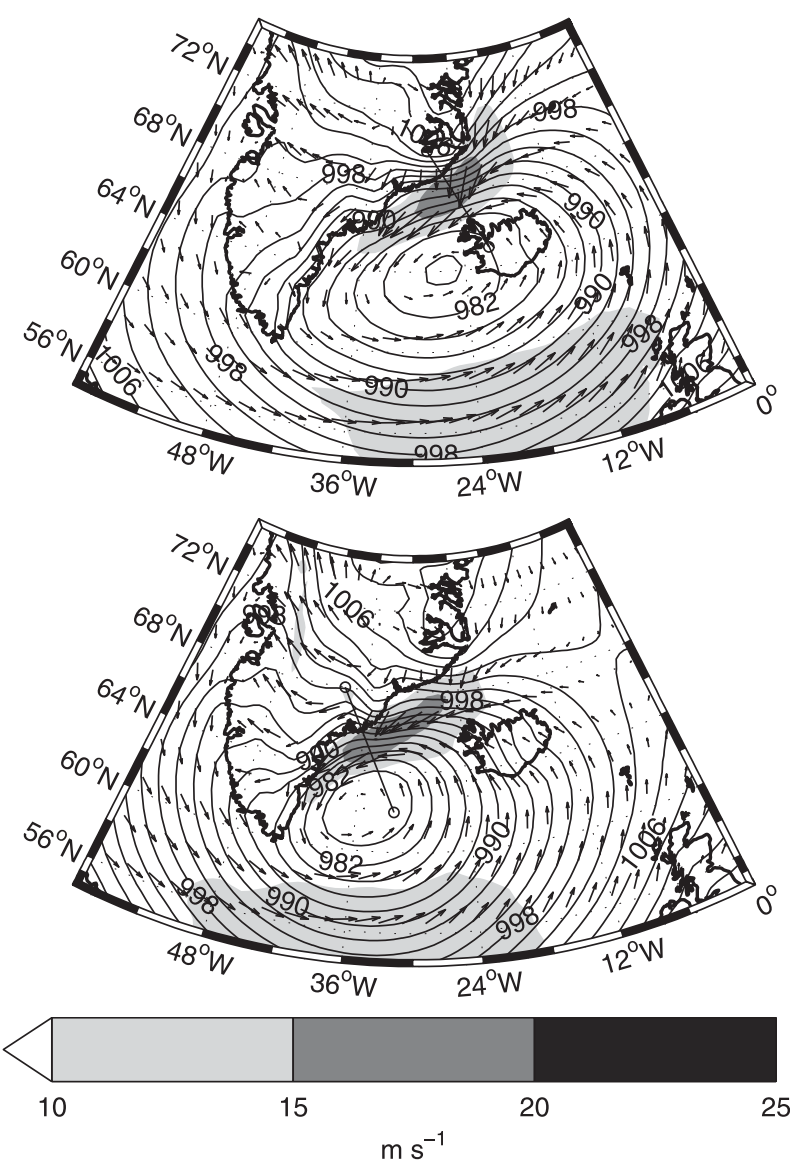

FIG. 8. Composite of $10-\mathrm{m}$ wind field $\left(\mathrm{m} \mathrm{s}^{-1}\right)$ for barrier wind events detected at (top) DSN and (bottom) DSS in DJF of the ERA-Interim dataset between 1989 and 2008. Wind vectors shown at every third data point. Composite mean sea level pressure (hPa, contours) shown every $2 \mathrm{hPa}$. Straight solid lines mark the locations for the cross sections shown in Fig. 9.

the sea ice, a feature that is especially important for barrier winds at DSN.

The barrier winds at both locations are forced by a composite low pressure of depth $980 \mathrm{hPa}$. For events at DSS, the location of this low is over the western Irminger Sea and for DSN it is farther to the northeast off the west coast of Iceland. The translation of the composite low is comparable to the translation of the centers of peak wind speeds and is further evidence that the barrier winds are produced due to the orography distorting the flow field of the cyclone. For events at DSN, the shape of the composite cyclone is more elongated along a southwest-northeast axis, implying a larger distribution of the centers of action of the member cyclones along this line. The fact that the location of the composite cyclone is over southwest Iceland for events at DSN could explain why the frequency of events at DSN is better correlated with the southwest Iceland mean sea level pressure record (and subsequently the NAO) than those at DSS.

Cross sections of the composite wind speed and potential temperature fields for events at DSN and DSS, taken perpendicular to the direction of flow through the region of maximum wind speed (see Fig. 8 for exact location), are shown in Fig. 9. The two composites show jet cores of $30 \mathrm{~m} \mathrm{~s}^{-1}$ at a height of $900 \mathrm{hPa}$ at DSN and $875 \mathrm{hPa}$ at DSS. This difference in jet core height is likely due to the 100 -hPa lower topography at DSN, which also produces a jet with lower overall height at DSN. The shapes of the composite barrier winds are also different. At DSN, the barrier wind structure is vertically aligned. In contrast, at DSS the barrier wind leans with height toward the coast, suggesting there is a larger cross-barrier flow near the mountain top that hems in the barrier wind. The shape of the composite barrier wind at DSN is reminiscent of the shape of the barrier winds observed on 2 and 6 March 2007 by Petersen et al. (2009) at the same location.

At both locations there is evidence of a near-neutral boundary layer with a stably stratified atmosphere above (as seen in Petersen et al. 2009). As was shown previously (Fig. 2), ERA-Interim tends to "blur out" the vertical
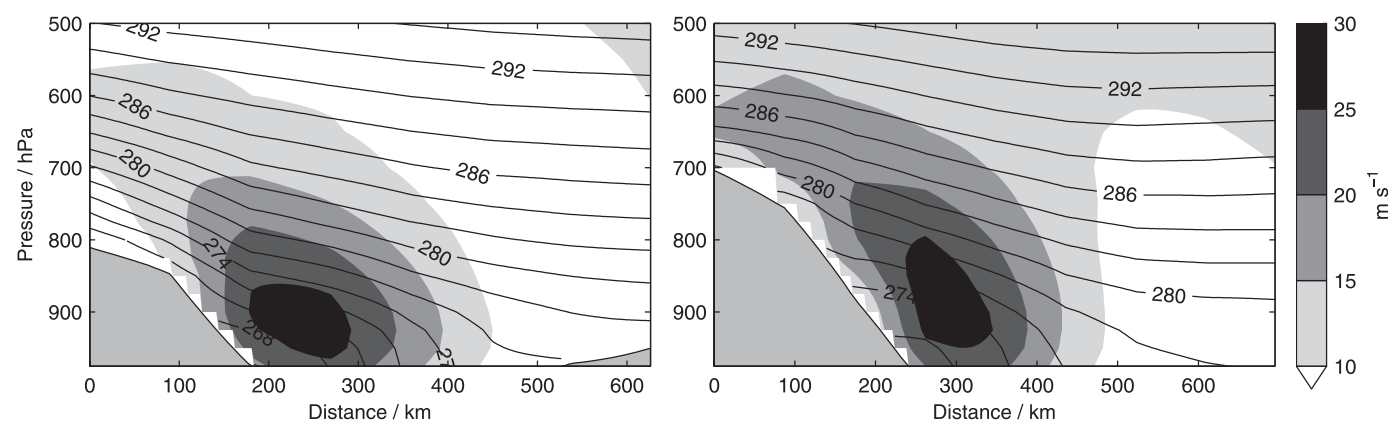

FIG. 9. Composite cross section of the barrier wind events at (left) DSN and (right) DSS for wind speed (shading, $\mathrm{m} \mathrm{s}^{-1}$ ) and potential temperature (K, contours every $2 \mathrm{~K}$ ). Cross section locations are shown in Fig. 8. 

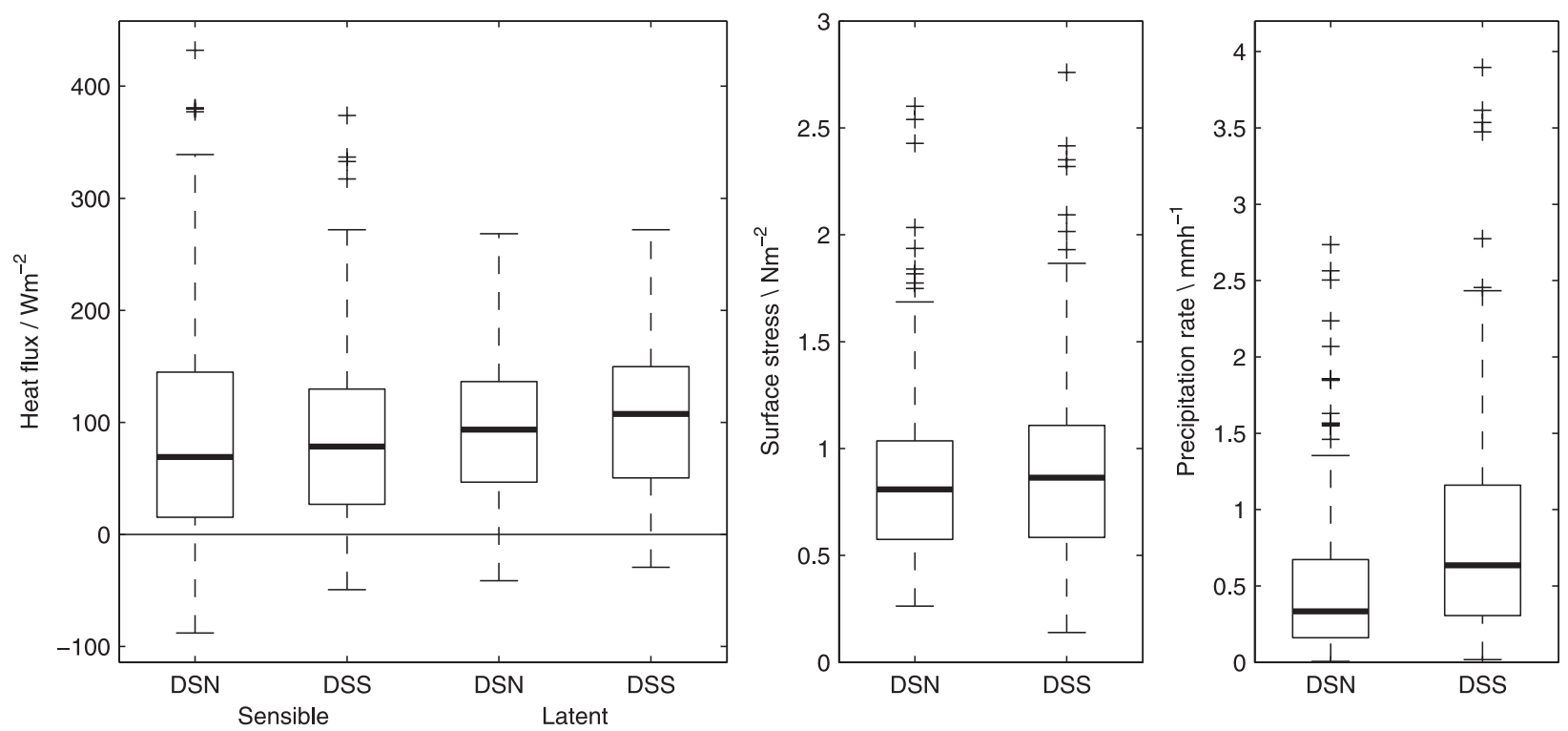

FIG. 10. (left) Mean (left column) sensible and (right column) latent heat fluxes ( $\mathrm{W} \mathrm{m}^{-2}$ ) for all events detected at DSS and DSN. Thick line is median, box indicates first and third quartiles, bars extend to the minimum and maximum of the dataset. Pluses for outliers defined as being 1.5 interquartile ranges outside of a quartile. Positive value indicates a flux of heat from the ocean into the atmosphere. (middle) Mean surface stress $\left(\mathrm{N} \mathrm{m}^{-2}\right)$ for each event in regions DSN and DSS. (right) Mean precipitation rate $\left(\mathrm{mm} \mathrm{h}^{-1}\right)$ for each event over the regions DSN and DSS.

structure of barrier winds, although the magnitude of the wind maxima is captured. Averaging over a number of events at each location is only likely to make this blurring worse in both wind speed and potential temperature. Indeed, manual inspection of individual cases confirmed this; many had much better defined potential temperature "inversion layers" with a range of heights.

\section{Surface fluxes}

To examine the potential impact on the ocean, surface turbulent heat fluxes, surface stress, and precipitation are investigated. In ERA-Interim these fields are provided as cumulative forecast fields that are run every $12 \mathrm{~h}$. As the analyses are produced every $6 \mathrm{~h}$, some processing is required to extract representative values at the same time steps as the analysis. This is achieved at 0000 and 1200 UTC by using the cumulative values for the following three hours. At 0600 and 1800 UTC, cumulative totals for the following three hours are used, but extracted from the forecast fields initialized at the previous 0000 and 1200 UTC. Clearly, this method relies on accurate forecast fields for a period of $9 \mathrm{~h}-$ a reasonable assumption. Note that all variables have been normalized by the length of the forecast to give mean heat fluxes in watts per square meter, surface stresses in newton per square meter, and precipitation rates in millimeter per hour.
The mean of the sensible and latent heat fluxes over each region (i.e., each box in Fig. 4) was calculated for each barrier wind event. Figure 10 shows the range of values found. The median values at both locations are around $100 \mathrm{~W} \mathrm{~m}^{-2}$ (from the ocean into the atmosphere) for both sensible and latent heat fluxes with the medians at DSS larger by about $20 \mathrm{~W} \mathrm{~m}^{-2}$ than at DSN. The effect of the 3-4-K colder temperatures of barrier wind events at DSN (Fig. 7) is being counteracted by colder seas and increased ice cover in this region (Fig. 3). What is notable in Fig. 10 are the large ranges. About half of these ranges are contained within $\pm 50 \mathrm{~W} \mathrm{~m}^{-2}$ of the median, but values as high as $300 \mathrm{~W} \mathrm{~m}^{-2}$ (more than $400 \mathrm{~W} \mathrm{~m}^{-2}$ in one case) or as low as $-50 \mathrm{~W} \mathrm{~m}^{-2}$ (i.e., a flux of heat from the atmosphere) are found as well. This shows us that at each location, the winds can be extracting as much as $600 \mathrm{~W} \mathrm{~m}^{-2}$ from the ocean averaged over each region or, at the other end of the spectrum, be losing $100 \mathrm{~W} \mathrm{~m}^{-2}$ to the ocean. The maximum heat fluxes in each region for each event (not shown) are commonly twice as large as the box-mean values, illustrating that twice as much heat flux is possible over localized regions.

It should be noted that the model outputs the fluxes of heat into the atmosphere and may not (because of the varying quantity of sea ice present) be interchangeable with fluxes out of the ocean. This discrepancy will be minor, as the fluxes of sensible and latent heat from the sea ice cover are dwarfed by those from the open ocean. 

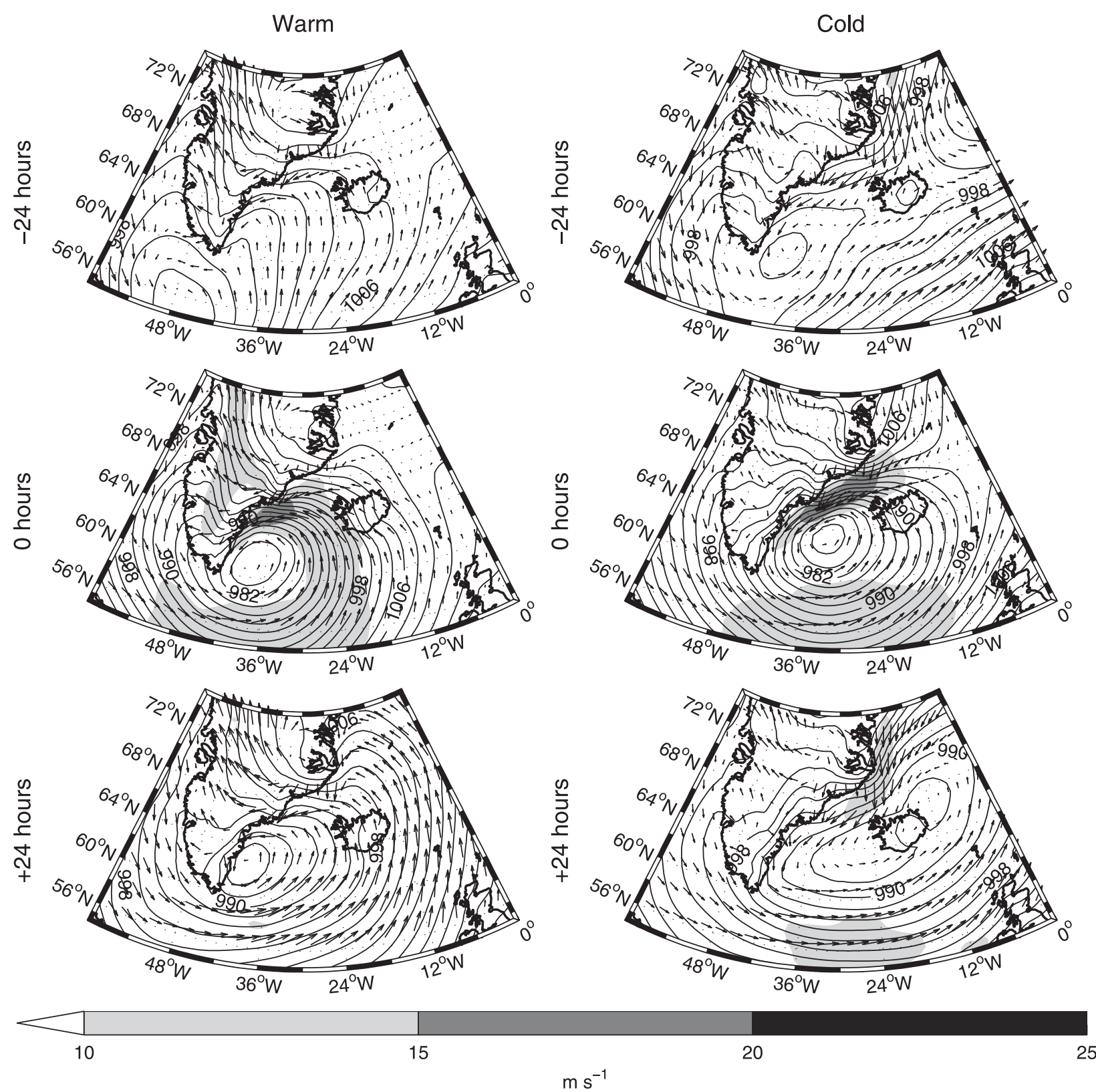

FIG. 11. Composite of 10-m wind field $\left(\mathrm{m} \mathrm{s}^{-1}\right.$ ) for (left) warm and (right) cold barrier winds at DSS. (middle row) Barrier winds at the time of peak wind speed. (top row),(bottom row) Composites $24 \mathrm{~h}$ before and after this time. Wind vectors shown at every third data point. Composite mean sea level pressure ( $\mathrm{hPa}$, contours) shown every $2 \mathrm{hPa}$.

However, this does mean that the area-average fluxes shown in Fig. 10 will be a lower bound for the fluxes from the open ocean.

The cause of the large ranges in the heat fluxes associated with the barrier wind events is the large range in 2-m temperatures (Fig. 7). More specifically, the controlling factor for these turbulent heat fluxes appears to be the temperature difference across the air-sea interface, $\Delta T$; correlation coefficients of 0.86 and 0.90 are found between the mean $\Delta T$ and the mean total turbulent heat flux in DSN and DSS, respectively. Insignificant correlation was found between the $10-\mathrm{m}$ wind speed and the turbulent heat fluxes, for the barrier wind events, despite heat fluxes being directly proportional to wind speed in the bulk formulas used to parameterize the fluxes. This is likely to be partially an artifact of the detection method; only a relatively small range of wind speeds are being sampled.

The mean surface stress and mean total precipitation rate for all barrier wind events over the DSN and DSS regions are also shown in Fig. 10. The median surface 

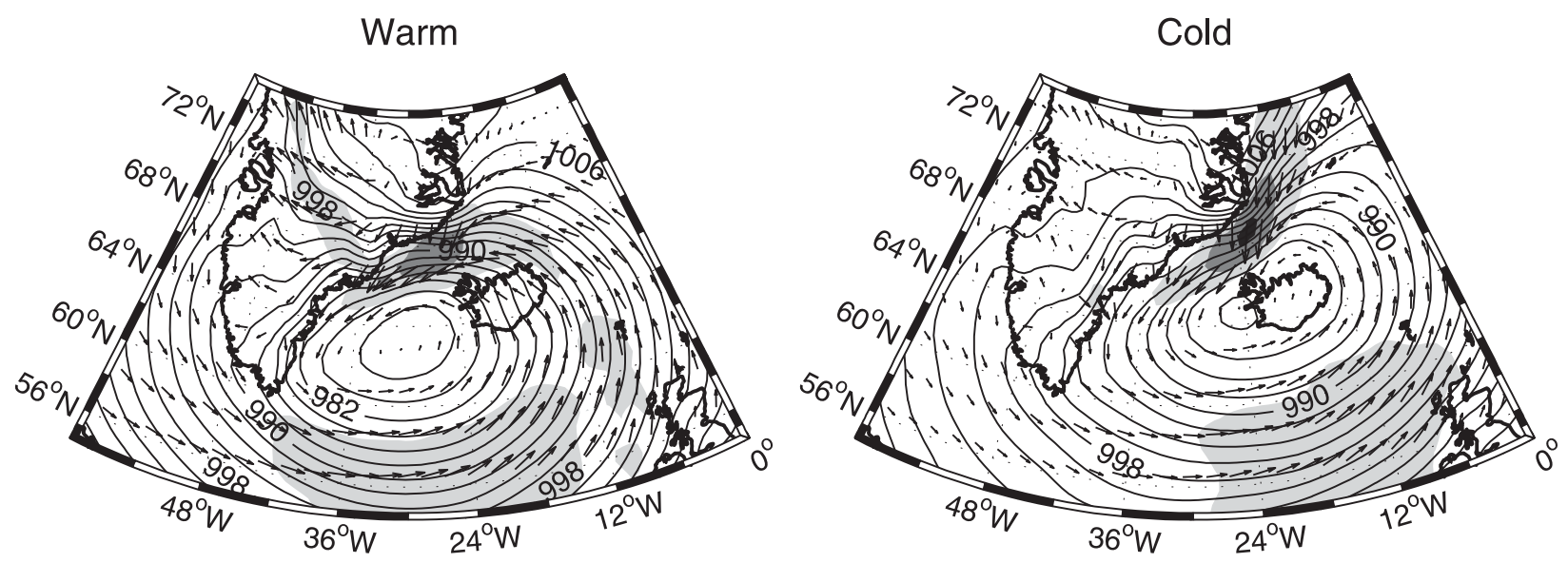

FIG. 12. Composite of $10-\mathrm{m}$ wind field ( $\mathrm{m} \mathrm{s}^{-1}$ ) for (left) warm and (right) cold barrier winds detected at DSN at zero lag time in DJF of the ERA-Interim dataset between 1989 and 2008. Wind vectors shown at every third data point. Composite mean sea level pressure (hPa, contours) shown every $2 \mathrm{hPa}$. Wind speed color bar as in Fig. 11.

stress for both locations is about $0.8 \mathrm{~N} \mathrm{~m}^{-2}$, but more than a quarter of the events experience mean stresses of more than $1 \mathrm{~N} \mathrm{~m}^{-2}$. The precipitation rate associated with barrier wind events is generally less at DSN than at DSS, with median values of 0.3 and $0.7 \mathrm{~mm} \mathrm{~h}^{-1}$, respectively. The reduced precipitation at DSN could be in part due to the more frequent ice cover at this location, reducing the moisture content of the air, and the smaller amount of uplift due to the lower topography. The range is also greater at DSS, the warmer location.

\section{Warm and cold barrier winds}

To examine the synoptic conditions that bring about the range of 2-m temperatures and hence heat fluxes, composites of warm and cold barrier winds were produced. There is a continuous spectrum of temperatures at both DSN and DSS (as seen via scatterplots e.g., not shown), so an obvious criterion for distinguishing two classes of barrier winds from temperature does not present itself. Instead, we will take the extreme quartiles of the 2-m temperature time series to classify warm and cold barrier wind events and illustrate these via composites. Each composite at DSN (DSS) contains 73 (63) events.

\section{a. Structure}

Warm barrier winds at DSS (Fig. 11, middle panels) are characterized by a composite low pressure center nearer to Cape Farewell than average (Fig. 8). The position of the composite cyclone channels air from the south into a band of southeasterly winds (greater than $10 \mathrm{~m} \mathrm{~s}^{-1}$ ) to the west of Iceland and into the barrier wind, which is as strong as (but more localized than) the average situation in Fig. 8.
In contrast, cold barrier winds at DSS have a composite low pressure center that is located farther northeast, closer to Iceland, and is $2 \mathrm{hPa}$ deeper. This location appears to restrict the band of southeasterly winds seen in the warm composite and instead favors the channeling of air from the north through the Denmark Strait and into a long barrier wind that extends almost the entire length of southeast Greenland (from DSN to DSS). The maximum wind speeds are also greater than both the warm and the total mean composites. It is worth noting that the 2 March 2007 GFDex case of Petersen et al. (2009) appears to be a clear example of a cold barrier wind at DSS - in terms of the synoptic situation, barrier flow structure, and observed temperatures.

The corresponding zero lag figures for DSN are very similar to those for DSS in all but location of activity (Fig. 12). In the warm class, the composite cyclone is to the west of Iceland in a similar position to the cold DSS composite but with a rather zonal major axis, so with significant southerly flow. In the cold class, the composite low is over Iceland and has a more southwest-northeast tilt, channeling (cold) air through the Denmark Strait. The 6 March 2007 GFDex case of Petersen et al. (2009) appears to be a clear example of a cold barrier wind at DSN. Similarities between the DSN and DSS events persist throughout the subsequent analysis, so for brevity only barrier winds at DSS will be considered from now on. It should be presumed that results are transferable to DSN through a translation of about $500 \mathrm{~km}$ northeastward along the Greenland coast.

Figure 11 also shows the temporal evolution of warm and cold barrier winds at DSS, which highlights further differences between the classifications. For warm barrier winds, the composite parent cyclone is located south of 

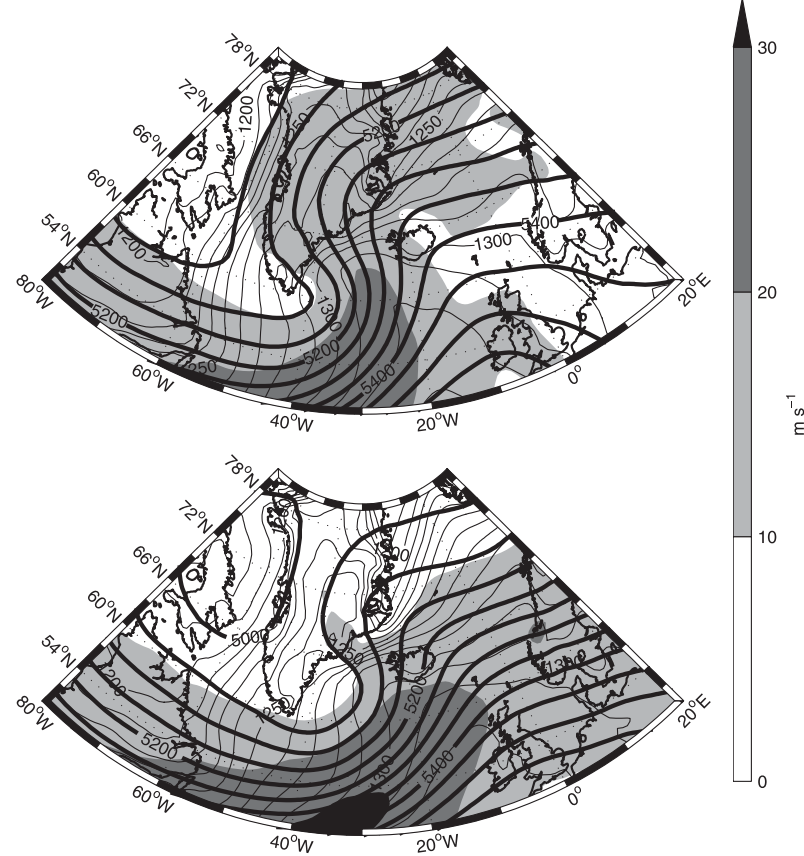

FIG. 13. Composite of $500-\mathrm{hPa}$ wind field ( $\mathrm{m} \mathrm{s}^{-1}$, colors) for (top) warm and (bottom) cold barrier winds detected at DSS for the winter months. Composite geopotential height ( $\mathrm{m}$, thick contours) shown every $50 \mathrm{~m}$ and $850-1000-\mathrm{hPa}$ thickness $(\mathrm{m}$, thin contours) shown every $10 \mathrm{~m}$. Note larger domain of this figure.

Cape Farewell $24 \mathrm{~h}$ previously, before moving into the lee of Greenland for the time of the peak barrier wind, and then appearing to become "captured" by Greenlandmoving no farther eastward over the next $24 \mathrm{~h}$. The lee of Greenland has been shown to be a region of cyclolysis (Petersen et al. 2003; Hoskins and Hodges 2002). The spreading isobars at the northeast part of the domain suggest this is not always the case and that some cyclones do move through the region.

For cold barrier winds, the parent cyclone begins just east of Cape Farewell and moves progressively northeastward throughout the $48 \mathrm{~h}$. The elongation and filling of the mean sea level pressure field at $+24 \mathrm{~h}$ is symptomatic of a range of translation speeds of the cyclones responsible for cold barrier winds. The cold barrier wind exists for a longer time; it is evident from -24 to $+24 \mathrm{~h}$, initially located at DSS and then at DSN, in agreement with the calculated phase lags (Fig. 6). In contrast, for the warm class, the barrier winds have a shorter life time.

The differing behavior of the surface lows can be explained in part through analyses at $500 \mathrm{hPa}$ (Fig. 13). Warm barrier winds have strong cross-barrier flow $\left(18 \mathrm{~m} \mathrm{~s}^{-1}\right)$ above mountain height, associated with a welldefined trough over the Labrador Sea and a ridge extending from the United Kingdom to east Greenland. This upper-level flow pattern would help confine a surface low to the Greenland coast and restrict its passage through the region. It will also assist in advecting warm air from the south toward DSS, resulting in barrier winds with warm cores.

For cold barrier winds, the upper-level trough is located farther east, over the west Irminger Sea, and the ridge over the United Kingdom is shallower (Fig. 13). The result is a weaker cross-barrier flow at $500 \mathrm{hPa}$; the upper-level winds are orientated more zonally and farther to the south, aiding the surface cyclones in passing through the region.

The composite 2-m temperature anomalies for the warm and cold cases are shown in Fig. 14. In the warm composite, the region is flooded with air warmer than the climatological mean (Fig. 3) by as much as $3 \mathrm{~K}$ over the ocean and $7 \mathrm{~K}$ over land, the result of both the lowlevel flow pattern and the strong cross-mountain flow at $500 \mathrm{hPa}$. This anomalously warm region extends from DSS both northwest and southeast, indicative of warm advection from the southeast and is in agreement with the strong southeasterlies both over sea and land in Fig. 11
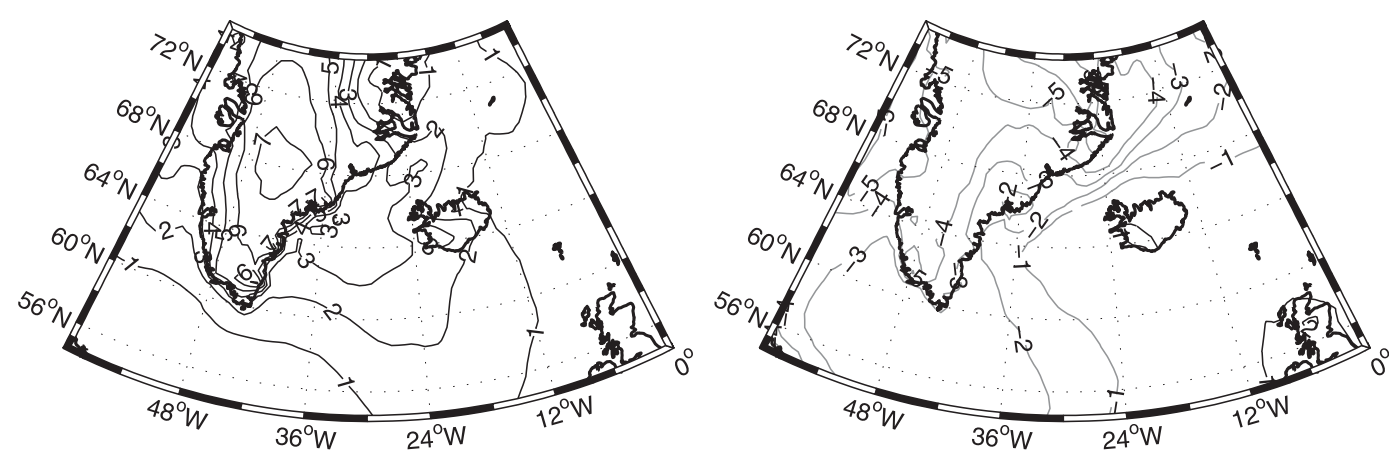

FIG. 14. Composite of $2-\mathrm{m}$ temperature anomaly ( $\mathrm{K}$, contours every $1 \mathrm{~K}$ ) for (left) warm and (right) cold barrier winds detected at DSS at zero lag time. Positive (negative) values shown with black (gray) lines. 

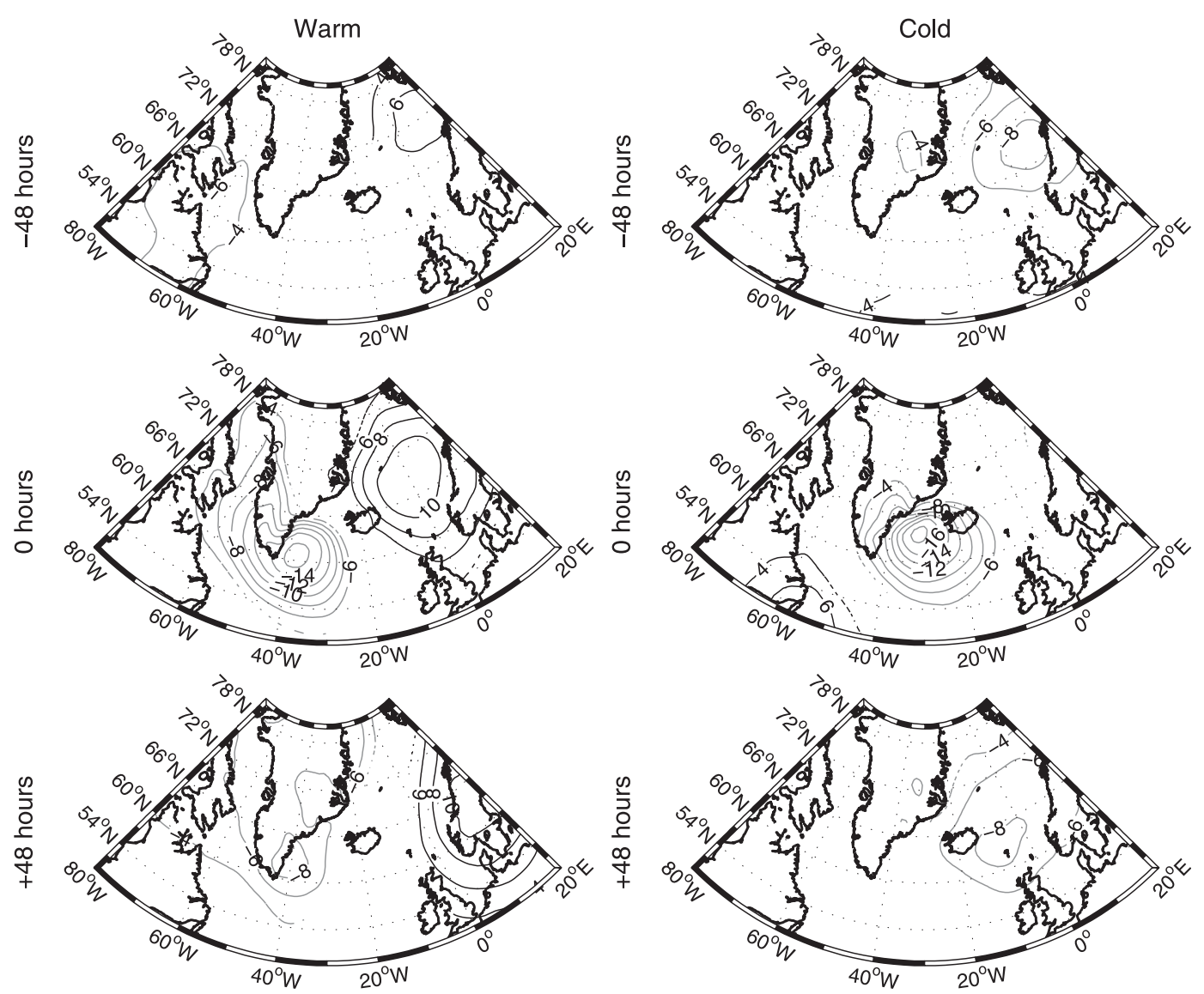

FIG. 15. Composite of the mean sea level pressure anomaly (hPa, contours every $1 \mathrm{hPa}$ ) for (left) warm and (right) cold barrier winds-at lag times of $-48,0$, and $+48 \mathrm{~h}$-detected at DSS in the winter months. Positive (negative) anomalies shown with black (gray) lines. Only values that are statistically significant at the $95 \%$ level are shown. Note the larger domain used.

The cold composite is characterized by an anomalously cold pool of $-4 \mathrm{~K}$ to the north of Iceland, with a tongue extending southward through the Denmark Strait to DSS. The shape of the cold anomaly, in conjunction with the cold dome of air in $1000-850-\mathrm{hPa}$ thickness along the east coast of Greenland (Fig. 13) and the long barrier wind seen in Fig. 11, is consistent with cold-air advection into the barrier wind from the northeast. These features of warm and cold barrier winds are corroborated by the $1000-850$-hPa thickness composites (Fig. 13) but are much less obvious in the 1000-500-hPa thickness composites (not shown), indicative of these features existing below mountain height.

Our interpretation of this analysis is that warm barrier winds source their air from the southerly advected warm pool, whereas even though the cold barrier winds have milder air advected toward them, they are fed by an even colder source of air, that is, a source northeast of the Denmark Strait. It appears that the cold barrier winds in particular have an offshore (i.e., downslope) contribution (see Fig. 11). At this stage it is not possible to say whether this minor contribution is simply a downslope deflection of maritime air or is a downslope density-driven (katabatic) flow of continental air.

These configurations are reminiscent of the classical and hybrid barrier winds along the coast of Alaska, described in Loescher et al. (2006) and Olson and Colle (2009). Our warm barrier winds are similar to their classical barrier winds that form due to the coastal deflection of onshore winds, whereas our cold barrier winds have similarities to their hybrid barrier winds that have an offshore gap flow component that turns to become coast parallel as it reaches the ocean. Hybrid barrier winds are colder than classical barrier winds because they source their air from an inshore cold pool and the onshore synoptic flow is advected over the cold core of the barrier wind. This is analogous to the maritime southeasterly flow being lifted over the cold Arctic flow seen in our cold barrier winds (see also Petersen et al. 2009, p. 1965). Apart from these structural 


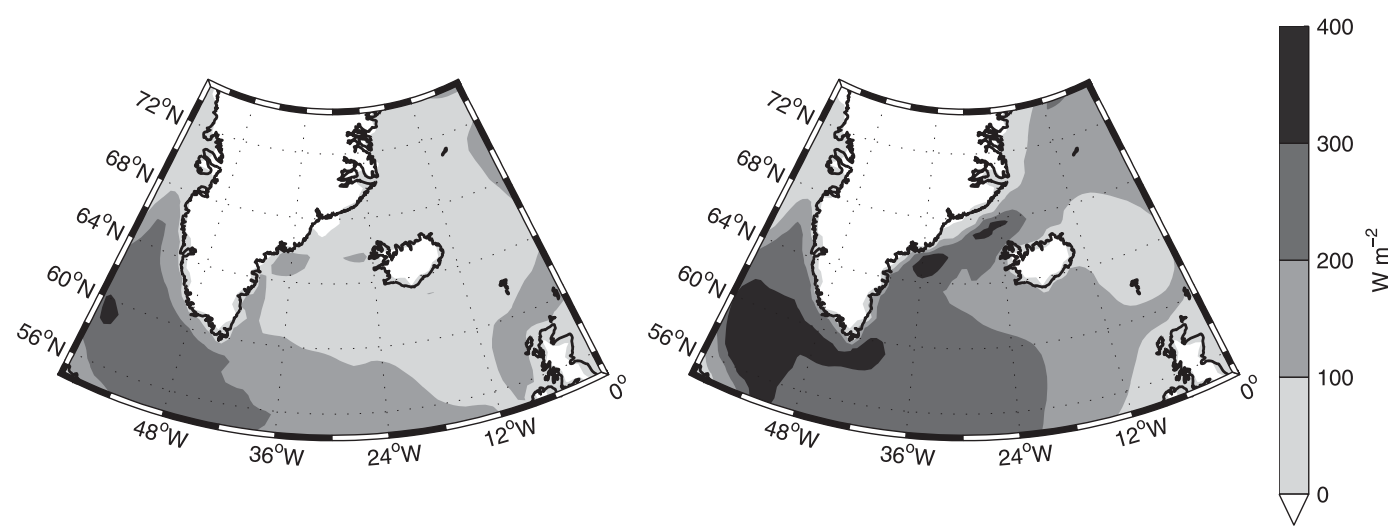

FIG. 16. Composite of total surface turbulent heat flux $\left(\mathrm{W} \mathrm{m}^{-2}\right)$ for (left) warm and (right) cold barrier winds detected at DSS at zero lag time.

similarities though, it is unclear at this stage how similar the dynamics of barrier winds around Greenland are to those found off Alaska-this is left to further investigation.

Returning to the mean sea level pressure composites (Fig. 11), it is apparent that there is not a great deal of difference in the strength or location of the parent cyclone for the two classes of barrier wind events (at zero lag). What is it about the synoptic environment then that brings about such different local conditions? Figure 15 shows the composite mean sea level pressure anomaly for warm and cold barrier winds at the time of peak winds at DSS and $48 \mathrm{~h}$ before and after. Only points that are statistically significant at the $95 \%$ level are shown. For the warm class, there is a significant high pressure anomaly of, at its peak, $10 \mathrm{hPa}$ located over the Nordic seas for the $96 \mathrm{~h}$ shown. This not only blocks the passage of the low responsible for the barrier wind but also acts to restrict cold, northerly flow along the east coast of Greenland. This configuration therefore favors warm advection from the south into the barrier winds. The fact that this anomalous high pressure can be found in a similar region throughout the 96-h period shown is indicative of North Atlantic blocking (Rex 1950; Pelly and Hoskins 2003) being important in the production of warm barrier winds. The blocking high at the surface at zero lag is consistent with the ridge at $500 \mathrm{hPa}$ seen in Fig. 13.

In contrast, the cold class is characterized by an anomalous low pressure system of $-10 \mathrm{hPa}$ over the Norwegian Sea $48 \mathrm{~h}$ before the peak barrier winds. This likely represents the signature from a previous cyclone that moved through the region and in so doing channeled cold air down the east coast of Greenland. As the cyclone responsible for the barrier wind moves into the region, it is steered by the upper-level zonal flow
(Fig. 13) and can channel this preconditioned cold air into a barrier wind. Forty-eight hours later, the cyclone has exited the region to the northeast. The fact that the pressure anomaly fields at lag times of $\pm 48 \mathrm{~h}$ are comparable suggests that this process may be repeated, providing a "conveyor belt" for channeling cold air from the Arctic down the southeastern coast of Greenland. This "train" of cyclones is reminiscent of the positive phase of the NAO. It is therefore unsurprising that the monthly frequency of cold barrier winds correlates (in a similar fashion to Fig. 5) with the monthly NAO index with a correlation coefficient of 0.35 . Cold events at DSN see a similar correlation of 0.39 . The warm barrier winds are produced by blocking highs; consequently, there is insignificant correlation between their monthly frequency and the NAO index at both locations.

\section{b. Impact}

The impact of these different temperature regimes can be seen in composites of the surface turbulent heat flux for the warm and cold barrier wind classes (Fig. 16). The cold class has a heat flux pattern that mirrors that of the wind speed composite. Total turbulent heat fluxes of more than $200 \mathrm{~W} \mathrm{~m}^{-2}$ are seen all the way down the southeastern coast of Greenland with bullets of nearly $400 \mathrm{~W} \mathrm{~m}^{-2}$ at, and upstream of, the DSS site. The largest heat fluxes are farther offshore than the wind speed maximum because of the influence of near-shore sea ice and a higher sea surface temperatures offshore. In the warm composite, only a small signature of scarcely more than $100 \mathrm{~W} \mathrm{~m}^{-2}$ is observed at the location of strongest winds. At all other places up the Greenland coast, the total heat flux is less than $100 \mathrm{~W} \mathrm{~m}^{-2}$. The two temperature regimes will therefore have very different impacts on the ocean. This is also true for the surface momentum flux (not shown), which is similar to 
the wind speed pattern (Fig. 11) and thus quite different for the warm and cold classes. In short, the specific synoptic environment in which Greenland barrier winds form is vital in determining the range and spatial distribution of both surface heat and momentum fluxes along the coast.

\section{Conclusions}

This climatology of barrier winds along the southeastern coast of Greenland has confirmed (see MR05) that there are two predominant regions where barrier winds frequently occur-referred to as Denmark Strait North (DSN) and South (DSS). During the $20 \mathrm{yr}$ of the climatology, barrier winds stronger than $20 \mathrm{~m} \mathrm{~s}^{-1}$ occur at both locations on average once a week in the winter months (DJF).

Good correlations were found between the monthly frequency of barrier winds and the monthly NAO index (especially at DSN). The relationship is explained in the following way. A high NAO index is the result of stronger and more frequent cyclones through the region, which are likely to trigger more and stronger barrier winds. It is possible that this correlation will potentially allow for the reconstruction of barrier wind frequency for periods of time before reanalysis are available.

One of the most striking features of the barrier winds investigated was the large range in 2-m temperaturessoutheast Greenland barrier winds cannot be said to be typically cold or warm winds. An investigation into the meteorological conditions responsible for the warmest and coldest barrier winds showed that blocking highs are responsible for channeling warm air into warm barrier winds and that trains of cyclones can consecutively channel cold air down the east coast of Greenland and into cold barrier winds. A very different pattern in the surface heat and momentum fluxes is seen for each temperature regime, and this shows the importance of the wider meteorological environment in understanding the local wind forcing in the region.

Acknowledgments. We thank the following people and organizations: The European Centre for MediumRange Weather Forecasts and the British Atmospheric Data Centre for providing the data; Bob Pickart for accommodating the launching of radiosondes on the Knorr cruise in October 2008; NCAS FGAM for providing the radiosonde equipment; Stefan Klink and Rudolf Krockauer from EUCOS for funding the radiosondes; Hreinn Hjartson from the Icelandic Met Office for providing equipment and assistance for radiosonde launches; Geraint Vaughan and Hugo Ricketts for radiosonde training; John Alberts and Eric Benway of WHOI for shipping equipment; and the radiosonde launchers for all their efforts in rough conditions.

\section{REFERENCES}

Bell, G. D., and L. F. Bosart, 1988: Appalachian cold-air damming. Mon. Wea. Rev., 116, 137-161.

Berrisford, P., D. Dee, K. Fielding, M. Fuentes, P. Kållberg, S. Kobayashi, and S. Uppala, 2009: The ERA-Interim archive. ERA Rep. Series, No. 1, ECMWF, 20 pp.

Braun, S. A., R. Rotunno, and J. B. Klemp, 1999: Effects of coastal orography on landfalling cold fronts. Part I: Dry, inviscid dynamics. J. Atmos. Sci., 56, 517-533.

Chen, W.-D., and R. B. Smith, 1987: Blocking and deflection of airflow by the Alps. Mon. Wea. Rev., 115, 2578-2597.

Colle, B. A., and C. F. Mass, 1995: The structure and evolution of cold surges east of the Rocky Mountains. Mon. Wea. Rev., 123, 2577-2610.

Cui, Z., M. Tjernström, and B. Grisogono, 1998: Idealized simulations of atmospheric coastal flow along the central coast of California. J. Appl. Meteor., 37, 1332-1363.

Doyle, J. D., and M. A. Shapiro, 1999: Flow response to large-scale topography: The Greenland tip jet. Tellus, 51A, 728-748.

Ebuchi, N., H. C. Graber, and M. J. Caruso, 2002: Evaluation of wind vectors observed by QuikSCAT/SeaWinds using ocean buoy data. J. Atmos. Oceanic Technol., 19, 2049-2062.

Haine, T. W. N., S. Zhang, G. W. K. Moore, and I. A. Renfrew, 2009: On the impact of high-resolution, high-frequency meteorological forcing on Denmark Strait ocean circulation. Quart. J. Roy. Meteor. Soc., 135, 2067-2085.

Heinemann, G., and T. Klein, 2002: Modelling and observations of the katabatic flow dynamics over Greenland. Tellus, $\mathbf{5 4 A}$, $542-554$.

Hoskins, B. J., and K. I. Hodges, 2002: New perspectives on the Northern Hemisphere winter storm tracks. J. Atmos. Sci., 59, 1041-1061.

Hurrell, J. W., 1995: Decadal trends in the North Atlantic Oscillation: Regional temperatures and precipitation. Science, 269, 676-679.

Klein, T., and G. Heinemann, 2002: Interaction of katabatic winds and mesocyclones near the eastern coast of Greenland. Meteor. Appl., 9, 407-422.

Kristjánsson, J. E., and H. McInnes, 1999: The impact of Greenland on cyclone evolution in the North Atlantic. Quart. J. Roy. Meteor. Soc., 125, 2819-2834.

Loescher, K. A., G. S. Young, B. A. Colle, and N. S. Winstead, 2006: Climatology of barrier jets along the Alaskan coast. Part I: Spatial and temporal distributions. Mon. Wea. Rev., 134, 437-453.

Martin, R., and G. W. K. Moore, 2006: Transition of a synoptic system to a polar low via interaction with the orography of Greenland. Tellus, 58A, 236-253.

Moore, G. W. K., 2003: Gale force winds over the Irminger Sea to the east of Cape Farewell, Greenland. Geophys. Res. Lett., 30, 1894, doi:10.1029/2003GL018012.

— , and I. A. Renfrew, 2005: Tip jets and barrier winds: A QuikSCAT climatology of high wind speed events around Greenland. J. Climate, 18, 3713-3725.

— R. S. Pickart, and I. A. Renfrew, 2008: Buoy observations from the windiest location in the world ocean, Cape Farewell, Greenland. Geophys. Res. Lett., 35, L18802, doi:10.1029/ 2008 GL034845. 
Olson, J. B., and B. A. Colle, 2009: Three-dimensional idealized simulations of barrier jets along the southeast coast of Alaska. Mon. Wea. Rev., 137, 391-413.

Outten, S. D., I. A. Renfrew, and G. N. Petersen, 2009: An easterly tip jet off Cape Farewell, Greenland. II: Simulations and dynamics. Quart. J. Roy. Meteor. Soc., 135, 1934-1949.

$\longrightarrow, \ldots$, and — 2010: Erratum: An easterly tip jet off Cape Farewell, Greenland. II: Simulations and dynamics. Quart. J. Roy. Meteor. Soc., 136, 1099-1101.

Parish, T. R., 1982: Barrier winds along the Sierra Nevada Mountains. J. Appl. Meteor., 21, 925-930.

—_ 1983: The influence of the Antarctic Peninsula on the wind field over the western Weddell Sea.J. Geophys. Res., 88, 2684 2692.

Pelly, J. L., and B. J. Hoskins, 2003: A new perspective on blocking. J. Atmos. Sci., 60, 743-755.

Petersen, G. N., H. Ólafsson, and J. E. Kristjánsson, 2003: Flow in the lee of idealized mountains and Greenland. J. Atmos. Sci., 60, 2183-2195.

_ J. E. Kristjánsson, and H. Ólafsson, 2005: The effect of upstream wind direction on atmospheric flow in the vicinity of a large mountain. Quart. J. Roy. Meteor. Soc., 131, 1113-1128.

_ I. A. Renfrew, and G. W. K. Moore, 2009: An overview of barrier winds off southeastern Greenland during the Greenland Flow Distortion Experiment. Quart. J. Roy. Meteor. Soc., 135, 1950-1967.

Pickart, R. S., M. A. Spall, M. H. Ribergaard, G. W. K. Moore, and R. F. Milliff, 2003: Deep convection in the Irminger Sea forced by the Greenland tip jet. Nature, 424, 152-156.

Pierrehumbert, R. T., and B. Wyman, 1985: Upstream effects of mesoscale mountains. J. Atmos. Sci., 42, 977-1003.

Rabier, F., J.-N. Thépaut, and P. Courtier, 1998: Extended assimilation and forecast experiments with a four-dimensional variational assimilation system. Quart. J. Roy. Meteor. Soc., 124, 1861-1887.

Renfrew, I. A., G. W. K. Moore, P. S. Guest, and K. Bumke, 2002: A comparison of surface layer and surface turbulent flux observations over the Labrador Sea with ECMWF analyses and NCEP reanalyses. J. Phys. Oceanogr., 32, 383-400.

- , and Coauthors, 2008: The Greenland Flow Distortion Experiment. Bull. Amer. Meteor. Soc., 89, 1307-1324.

— off Cape Farewell, Greenland. I: Aircraft observations. Quart. J. Roy. Meteor. Soc., 135, 1919-1933.
—, G. N. Petersen, D. A. J. Sproson, G. W. K. Moore, H. Adiwidjaja, S. Zhang, and R. North, 2009b: A comparison of aircraft-based surface-layer observations over Denmark Strait and the Irminger Sea with meteorological analyses and QuikSCAT winds. Quart. J. Roy. Meteor. Soc., 135, 2046-2066.

Revell, M. J., J. H. Copeland, H. R. Larsen, and D. S. Wratt, 2002: Barrier jets around the southern Alps of New Zealand and their potential to enhance alpine rainfall. Atmos. Res., 61, 277-298.

Rex, D. F., 1950: Blocking action in the middle troposphere and its effect upon regional climate. I. An aerological study of blocking action. Tellus, 2, 196-211.

Sahsamanoglou, H. S., 1990: A contribution to the study of action centres in the North Atlantic. Int. J. Climatol., 10, 247-261.

Sampe, T., and S.-P. Xie, 2007: Mapping high sea winds from space: A global climatology. Bull. Amer. Meteor. Soc., 88, 1965-1978.

Schwerdtfeger, W., 1975: The effect of the Antarctic Peninsula on the temperature regime of the Weddell Sea. Mon. Wea. Rev., 103, 45-51.

Serreze, M. C., F. Carse, R. G. Barry, and J. C. Rogers, 1997: Icelandic low cyclone activity: Climatological features, linkages with the NAO, and relationships with recent changes in the Northern Hemisphere circulation. J. Climate, 10, 453-464.

Skeie, R. B., J. E. Kristjánsson, H. Olafsson, and B. Røsting, 2006: Dynamical processes related to cyclone development near Greenland. Meteor. Z., 15, 147-156.

Smith, S. D., 1988: Coefficients for sea surface wind stress, heat flux, and wind profiles as a function of wind speed and temperature. J. Geophys. Res., 93, 15 467-15 472.

Sproson, D. A. J., I. A. Renfrew, and K. J. Heywood, 2008: Atmospheric conditions associated with oceanic convection in the south-east Labrador Sea. Geophys. Res. Lett., 35, L06601, doi:10.1029/2007GL032971.

Straneo, F., G. S. Hamilton, D. A. Sutherland, L. A. Stearns, F. Davidson, M. O. Hammill, G. B. Stenson, and A. RosingAsvid, 2010: Rapid circulation of warm subtropical waters in a major glacial fjord in east Greenland. Nat. Geosci., 3, 182-186.

Våge, K., R. S. Pickart, G. W. K. Moore, and M. H. Ribergaard, 2008: Winter mixed layer development in the central Irminger Sea: The effect of strong, intermittent wind events. J. Phys. Oceanogr., 38, 541-565.

— T. Spengler, H. C. Davies, and R. S. Pickart, 2009: Multi-event analysis of the westerly Greenland tip jet based upon 45 winters in ERA-40. Quart. J. Roy. Meteor. Soc., 135, 1999-2011. 